\title{
Prognóstico do vento para o estado de alagoas utilizando o modelo wrf em alta resolução: avaliação da melhoria da topografia, uso do solo e velocidade de fricção
}

\author{
Prognosis of the wind for alagoas state using wrf model: study of the update \\ topography, land use and friction velocity
}

\author{
Rosiberto Salustiano Da Silva Junior ${ }^{1}$, Roberto Fernando Fonseca Lyra ${ }^{1}$, \\ Diogo Nunes Da Silva Ramos², Marcos Antonio Lima Moura ${ }^{3}$, Heliofabio Barros Gomes ${ }^{3}$ e \\ Sandro Correia Holanda ${ }^{4}$ \\ rosibertojr@gmail.com; roberto.ufal@gmail.com; diogonsramos@gmail.com; malm@ccen.ufal.br; heliofab@gmail.com; sandro- \\ cholanda@gmail.com
}

\author{
${ }^{1}$ Professor Doutor, Instituto de Ciências Atmosféricas, UFAL, Maceió/AL, Brasil \\ ${ }^{2}$ Doutorando, Instituto Nacional de Pesquisas Espaciais, INPE, Cachoeira Paulisata/SP, Brasil \\ ${ }^{3}$ Professor Doutor, Instituto de Ciências Atmosféricas, UFAL, Maceió/AL, Brasil \\ ${ }^{4}$ Professor Doutor, Centro de Ciências Agrárias, UFAL, Maceió/AL, Brasil
}

\begin{abstract}
Resumo
O presente trabalho visa fazer um estudo avaliativo das atualizações de topografia, uso do solo e velocidade de fricção realizadas no modelo atmosférico WRF, e comprovar sua eficiência em simular os padrões de velocidade e direção do vento utilizando medições da estação anemométrica de Maragogi/AL, durante o período de agosto/2007 a julho/2008, com enfoque ao mês de maio/2008 que apresentou baixos índices de coeficiente de correlação. As mudanças realizadas resultaram em melhorias no coeficiente de correlação para a velocidade do vento de 0,15 para 0,61, contudo está melhoria não foi percebida para a direção do vento. Pode-se destacar também o fato que a topografia e a velocidade de friç̧ão foram as variáveis que mais influenciaram nas simulações, tendo em vista que a pouca diferença entre a condição padrão do modelo e atualizada com relação ao uso do solo. A velocidade média do vento predominante para o município de Maragogi/AL foi de $5,27 \mathrm{~m} / \mathrm{s}$ e direção predominante do vento de Sudeste. Em geral notou-se melhora nas simulações quando implementadas as atualizações no modelo.
\end{abstract}

Palavras-Chave: Energia Eólica, Modelos Atmosféricos.

\begin{abstract}
This paper aims to make an evaluative study of the updates topography, land use and friction velocity performed in the atmospheric WRF model, and prove its efficiency in simulating the wind speed and direction patterns using measurements of anemometric station Maragogi/AL, during the period from August/2007 to July/2008, focusing to May/2008 showed low correlation coefficient indices. The changes resulted in improvements made in the correlation coefficient for the wind speed of 0.15 to 0.61 , however it is not perceived improvement to the wind direction. Highlighted the fact that the topography and friction velocity were the variables that most influenced the simulations, however there was little difference between the default condition the update condition for land use. The average speed for the city of Maragogi/AL was 5,27m/s predominant direction of South East wind. Generally noticed an improvement in the simulations when implemented updates in the model.
\end{abstract}

Keywords: Wind Energy, Atmospheric Model. 
$\mathrm{A}$ infraestrutura elétrica, é um tema que vem causando preocupação diante da alta dependência dos recursos hídricos para geração de energia (RAMOS, 2013). De acordo com o Balanço Energético Nacional 2014 (MME, 2014), as usinas hidrelétricas correspondem a $64.9 \%$ da matriz elétrica total.

O Brasil possui um potencial eólico estimado de 143,5 GW no nível de 50 metros de altura (AMARANTE, et al., 2001), mas este valor pode ser maior, principalmente com a possibilidade de exploração do potencial offshore e utilização de aero gerador com altura acima de $50 \mathrm{~m}$, onde os efeitos da superfície tendem a ser menores.

A região Nordeste Brasileiro (NEB) possui 75 GW, o maior potencial eólico estimado do Brasil, concentrado principalmente nas áreas costeiras, onde se localiza maior parte da população urbana. Mas a principal característica desta região é a complementaridade com a fonte hídrica, durante a estação seca quando a vazão do Rio São Francisco é reduzida a sazonalidade é favorável para a produção eólica (FILGUEIRAS e SILVA, 2003; ELETROBRÁS, 2008).

Os modelos atmosféricos têm sido uma importante ferramenta para descrever e caracterizar uma determinada área sem a necessidade da instalação de uma enorme rede de estações meteorológicas. Marchi em 2011 encontrou dificuldades em suas simulações, pelo fato do WRF representar de uma forma errada a topografia e uso do solo de algumas regiões.

A velocidade de fricção $(u *)$ e o comprimento de rugosidade $\left(z_{0}\right)$ são termos referentes às características da superfície terrestre, também chamado de parâmetros aerodinâmicos. A obtenção de $\mathrm{u}$ * é realizada através da Teoria da Similaridade de Monin-Obukhov (MONIN OBUKHOV, 1954; FOKEN, 2006). Várias equações que descrevem o estado da atmosfera dependem da velocidade de fricção, como no caso dos fluxos na camada limite superfície, teoria de Monin Obukhov, e a descrição da camada limite convectiva.

O objetivo desta proposta é avaliar o aumento da resolução da topografia e uso do solo, além de avaliar a diminuição do valor de truncamento da velocidade de fricção do vento de $0,1 \mathrm{~m} / \mathrm{s}$ para $0,0001 \mathrm{~m} / \mathrm{s}$

\section{Material e métodos}

A área de estudo é o município de Maragogi que está localizado no litoral Norte do estado de Alagoas/Brasil (estação anemométrica $8,9856^{\circ} \mathrm{S}$ e $35,2006^{\circ} \mathrm{O}$, e altura de $48 \mathrm{~m}$ acima do nível médio do mar), ver figura 01. A escolha dessa área está ligada primeiramente ao fato de ser uma área de transição entre oceano e continente, de modo a avaliar o efeito da variabilidade da rugosidade sobre a velocidade de fricção. Outro fator seria a disponibilidade de dados observados em torres anemométricas instaladas, mas principalmente pelo fato do NEB ser a região de maior potencial eólico no território nacional (Amarante et al., 2001; Silva et al., 2005; Pereira et al., 2008).

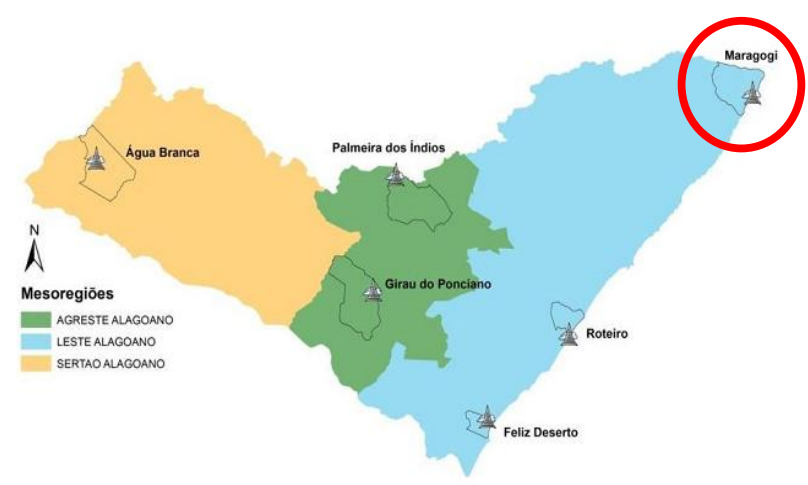

Figura 01: Localização da estação anemométrica de Maragogi no estado de Alagoas/Brasil.

\subsection{Configuração do Modelo}

Para o estudo foi adotado o modelo atmosférico de mesoescala Weather Research and Forecasting (WRF) na versão 3.2, lançada em abril de 2010. As condições de contorno do modelo foram feitas com dados de reanalise do NCEP, Final Analysis (FNL).

Foi configurado com dois domínios, definidos como: Domínio 1 - abrange parte do NEB e Oceano Atlântico, possui resolução espacial de $25 \mathrm{~km}$; Domínio 2 - Todo o estado de Alagoas, sul de Pernambuco e parte do oceano Atlântico, com resolução de $5 \mathrm{~km}$. Configuração esta que aumenta a qualidade das simulações, pois os domínios que compreendem maior área irão descrever fenômenos da escala sinótica, como deslocamento de sistemas frontais do sul, mecanismos convectivos do continente africano, ventos alísios de nordeste e sudeste.

\section{3 - Aumento da Resolução da Topografia e Uso do Solo}

Para melhorar a descrição superficial do WRF foi realizada uma atualização da topografia e uso do solo, com os dados do Projeto Brasil em Relevo. Este incluiu como fonte primária os modelos de elevação digital, com aproximadamente 90 metros de resolução espacial, originários da missão de mapeamento do relevo terrestre SRTM (Shuttle Radar Topography 
Mission), desenvolvido pela NASA (National Aeronautics and Space Administration) e NGA (National Geospatial-Intelligence Agency) dos Estados Unidos no ano 2000. Analisando especificamente a região do município de Maragogi/AL (figuras $2 \mathrm{~A}$ e 2B), fica evidenciado a melhora no detalhamento da topografia.
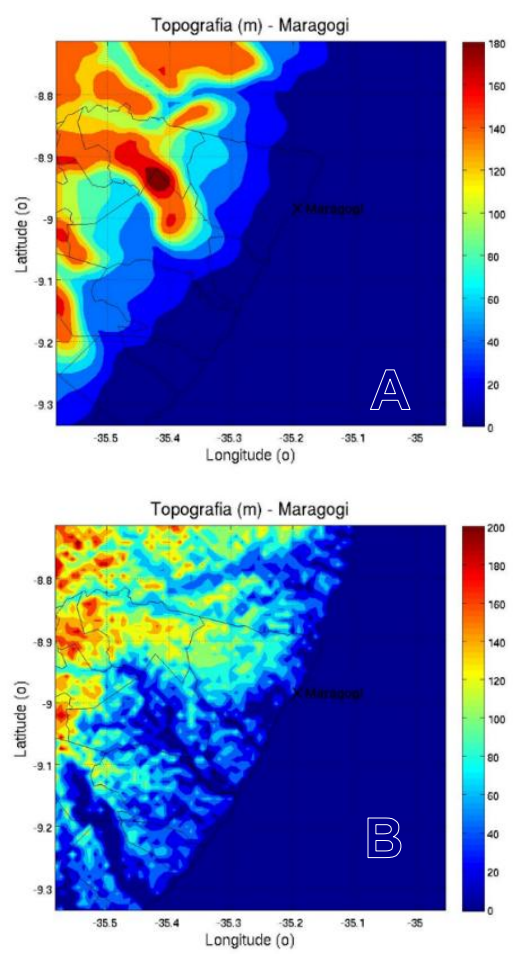

Figura 02 - Topografia da área de estudo, (A) configuração padrão do modelo e (B) atualizada.

O mesmo aconteceu na atualização realizada para o uso do solo, onde a descrição do tipo de solo na configuração padrão do modelo está datado de 1992 com resolução horizontal de $1 \mathrm{~km}$, e a atualização proposta faz referência ao ano de 2001 com resolução horizontal de $0,25 \mathrm{~km}$. Os dados obtidos para atualização do uso do solo tem como base o Programa Internacional Geosfera Biosfera (http://webmap.ornl.gov/wcsdown/wcsdown.jsp?dg_i $\mathrm{d}=10004 \_1$ - "IGBP global vegetation classification scheme").

\section{4 - Dados para Validação das Simulações}

Através do convenio (ECV-156/2005) entre as Centrais Elétricas Brasileiras -ELETROBRAS, Instituto de Tecnologia para o Desenvolvimento - LACTEC e Universidade Federal de Alagoas - UFAL foi desenvolvido o projeto "Atlas Eólico e Disseminação da Tecnologia Eólica no Estado de Alagoas" em 2007. Após um mapeamento prévio do vento (ELETROBRÁS, 2008), foram escolhidos seis locais onde foram instaladas estações anemométricas, cobrindo espacialmente as três mesorregiões do Estado (figura 01). A torre foi instalada com um sistema de aquisição de dados (datalogger) modelo CR800-series da Campbell Scientific inc. (EUA), funcionando com eletricidade gerada através de um painel fotovoltaico, modelo KS-20 da Kyocera. A velocidade do vento foi medida por um anemômetro tipo cocha de copo classe I, modelo A100L2, e o sensor de direção do vento utilizado foi o W200P, ambos confeccionados pela empresa (Vetor InstrumentsPais).

Os dados utilizados foram coletados entre Agosto/2007 a Julho/2008, coincidindo com o mesmo intervalo usado na elaboração do Atlas Eólico do Estado de Alagoas - AEEA (ELETROBRÁS, 2008). E para avaliar a velocidade de fricção será utilizado o mês de pior representatividade desta variável, o mês de maio de 2008.

\section{5 - Modelo de Mesoescala WRF}

\section{(Skamarock, et al., 2005)}

Para responder quais são as regiões indicadas para uma possível instalação de um parque eólico, utilizamos o modelo de mesoescala WRF durante o período de agosto/07 a julho/08, e utilizamos os dados da ELETROBRÁS para fazer a validação das simulações. $O$ intuito de utilizar o modelo de mesoescala WRF foi avaliar todo o Estado de Alagoas e identificar as áreas promissoras e em seguida fazer estudos mais detalhados utilizando modelos de microescala, que incorpora em suas simulações variações local dos padrões do vento (topografia, rugosidade e obstáculos).

\section{Resultados e discussões}

Na figura 04 é apresentada a variação temporal da velocidade para a estação de Maragogi compara a simulação feita com o WRF, os resultados mostraram que o modelo também conseguiu representar as variações na velocidade do vento, mas com exceção do período compreendido em maio à junho/2008. 


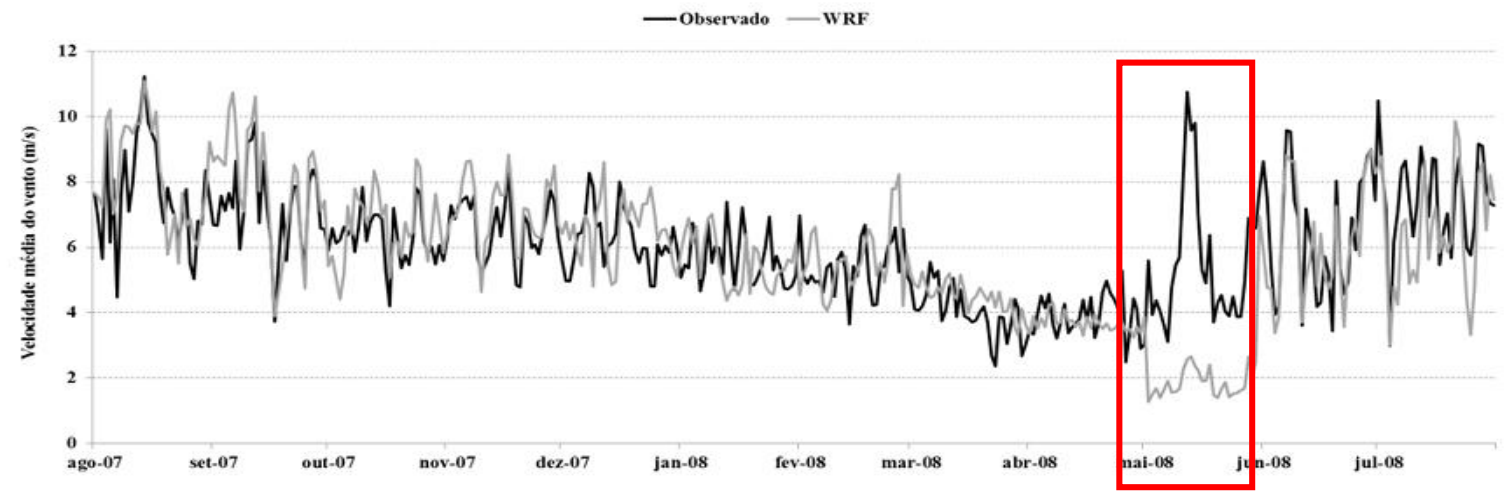

Figura 04: Média diária da velocidade do vento observado e estimado pelo WRF em Maragogi. Fonte: Ramos, 2012.

Ainda com base na figura 04, pode-se notar no destaque que o modelo apresentou grandes dificuldades em simular a velocidade do vento nos meses de maio e junho de 2008, pois enquanto houve aumento da velocidade do vento o modelo registrou diminuição da velocidade. Portanto, supondo que os motivos dessas dificuldades tenham ocorrido pela má representação da topografia, uso do solo e truncamento do valor da velocidade de fricção, decidiu-se atualizar estas informações no modelo e avaliar a melhoria da simulação para o mês de maio de 2008.

Inicialmente analisando o impacto da atualização da topografia, uso do solo e velocidade de fricção, a figura 05 mostra a validação feita para a variável direção do vento para as situações com dados observados, simulação com configuração padrão (wrf_new) e simulação com atualização da topografia, uso do solo, e velocidade de fricção (wrf_old). Com base na figura 05 é possível notar que existe pouca diferença para a variável direção do vento a atualização realizada, e nas duas simulações realizadas o modelo conseguiu representar com êxito a direção predominante do vento que foi de Sudeste, para o mês de maio de 2008. Notou-se também que nos períodos entre 11/05 - 17/05/2008 e de 28/05 01/06/2008 houve uma forte tendência do vento soprar de Sudeste, com pouquíssima variabilidade na direção do vento. Possivelmente algum fenômeno de grande escala esteve atuando nestes dias, como por exemplo os Ventos Alísios.

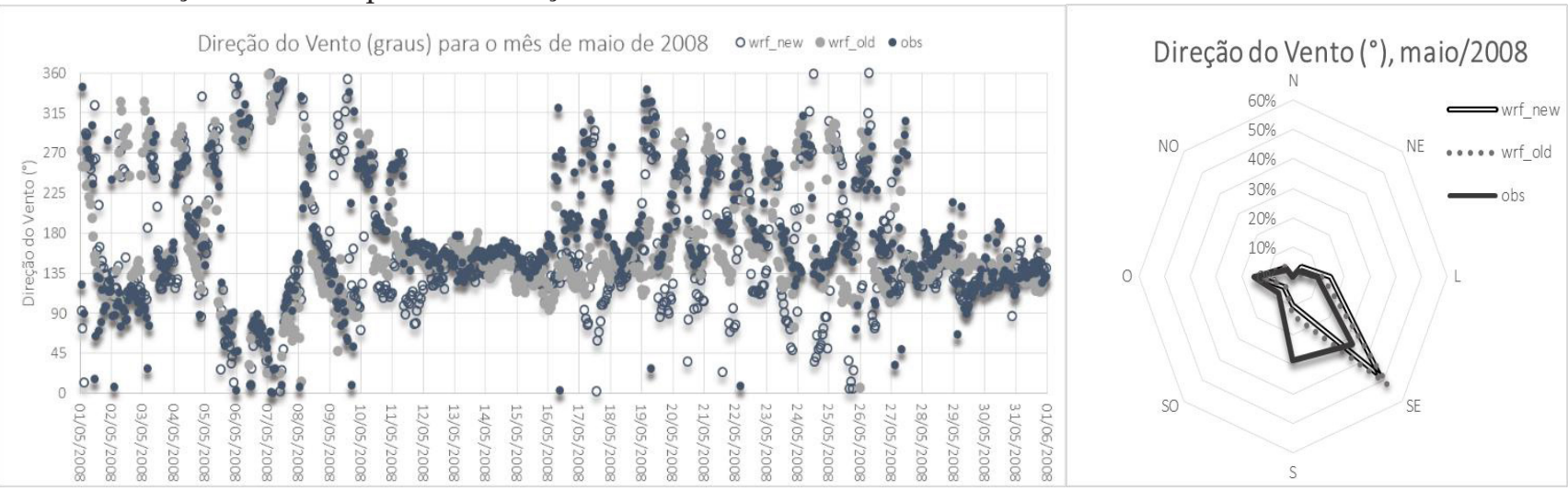

Figura 05: Validação da estimativa da direção do vento para o município de Maragogi/AL. Sendo "Obs - dados observados", "wrf_old - simulações utilizando o modelo WRF, com a configuração padrão", "wrf_new simulações utilizando o modelo WRF, com atualizações de topografia, uso do solo e velocidade de fricção".

Os ventos locais sofrem influência de diversos parâmetros do lugar, e estes devem ser conhecidos quando se deseja estimar os padrões do vento. Os fatores que influenciam o perfil vertical do vento são: obstáculos, rugosidade do terreno e orografia. Ainda com base em ARYA, 2001, a intensidade do vento é inversamente proporcional a rugosidade e seu efeito é expresso diretamente na velocidade de friç̧ão. E terrenos acidentados são caracterizados pela presença de elevações e depressões, e podem influenciar diretamente na intensidade e direção do vento.

A área de estudo está situada numa zona de transição do oceano para o continente, e a melhoria da topografia e uso do solo, aliada a melhor detalhamento da velocidade de fricção do vento, possivelmente deve ter tornado as simulações mais 
próximas da realidade, lembrando que o coeficiente $d \epsilon$ atrito de mares e lagos varia entre $0,0001 \mathrm{~m}-0,001 \mathrm{~m}$ enquanto para muita arvores e arbusto o coeficient de atrito seria de $0,2 \mathrm{~m}$, como é o caso do sitio experimental desse estudo.

De acordo com a tabela 01, não existe grande diferença entre a configuração padrão e a atualizada, com relação ao uso do solo, pois em ambas as situações simuladas a área considerada é de plantio agrícola, vale destacar o fato que a atualização do uso do solo, é considerado que o entorno é de vegetação natural e anteriormente essa consideração não existia. Já com relação a topografia, nota-se uma diferença grande entre a simulação padrão e a atualizada, onde a simulação atualizada considera a altura de $30 \mathrm{~m}$ e a antiga somente $3,8 \mathrm{~m}$, o que confere as novas simulações uma maior precisão quando comparado ao observado (48m de acordo com o Google Earth). Possivelmente o erro na consideração na altura da superfície irá alterar os padrões de velocidade e direção do vento, além de considerar também que no entorno da área simulada considera de forma acertada a existência de vegetação natural, enquanto que em simulações anteriores isso não ocorria.

Destaca-se ainda o fato da área de estudo estar situada a $640 \mathrm{~m}$ de distância da praia (oceano Atlântico), que estaria ao nível médio do mar $(0 \mathrm{~m})$, ou seja, a altura do relevo simulado anteriormente de $3,8 \mathrm{~m}$ estaria longe do observado que é de $48 \mathrm{~m}$, que foi corrigido parcialmente com a atualização, pois as simulações passaram a considerar uma topografia com altura de $30 \mathrm{~m}$.

Tabela 01: Características da área de estudo do município de Maragogi, Altura do relevo e uso do solo.

\begin{tabular}{l|c|c|c}
\hline & $\begin{array}{c}\text { Observado } \\
\text { (Google } \\
\text { Earth) }\end{array}$ & WRF_old & WRF_new \\
\hline $\begin{array}{l}\text { Altura do } \\
\text { Relevo }\end{array}$ & $48 m$ & $3,8 m$ & $30 m$ \\
\hline Uso do Solo & $\begin{array}{c}\text { Plantação de } \\
\text { Cana-de- } \\
\text { açúcar }\end{array}$ & $\begin{array}{c}\text { Cultura } \\
\text { Agrícolas }\end{array}$ & $\begin{array}{c}\text { Cultura } \\
\text { Agrícolas / } \\
\text { mosaico de }\end{array}$ \\
\hline
\end{tabular}

\begin{tabular}{c|c|c}
$\begin{array}{c}\text { cercada de } \\
\text { vegetação } \\
\text { natural }\end{array}$ & $\begin{array}{c}\text { Vegetação } \\
\text { natural }\end{array}$ \\
\hline
\end{tabular}

Obs.: A Estação Anemométrica de Maragogi está localizada no litoral Norte de Alagoas e distante $640 \mathrm{~m}$ do mar.

Uma localidade é considerada boa para a instalação de parques eólicos, quando oferece ao sistema de produção eletricidade ventos soprando de forma constante durante todo o ano. Usualmente, a geração elétrica se inicia com velocidades de vento da ordem de 2,5 - 3,0 m/s; abaixo desses valores o conteúdo energético do vento não justifica o aproveitamento. Velocidades superiores a aproximadamente $12,0-15,0 \mathrm{~m} / \mathrm{s}$ ativam o sistema automático de limitação de potência da máquina, dependendo do modelo de turbina (ELETROBRÁS, 2008). Com base no ATLAS Eólico alagoano, mostra que a região do município de Maragogi tem intensidade média anual do vento em torno de 5,5 e $6,0 \mathrm{~m} / \mathrm{s}$, nas alturas de 75 e $100 \mathrm{~m}$. A medições e simulações realizadas para $30 \mathrm{~m}$ de altura, apontaram velocidade média do vento de $5,27 \mathrm{~m} / \mathrm{s}$ (OBS) para o mês de maio/2008, enquanto que as simulações superestimaram a velocidade média de $6,25 \mathrm{~m} / \mathrm{s}$ (wrf_new) e 5,97m/s (wrf_old).

Antes da instalação de um parque eólico se faz necessário a realização de estudo de uma região para identificar área promissoras em termos de vento. E estes estudos são realizados utilizando torres anemométricas e modelos atmosféricos, porém os modelos atmosféricos muitas vezes apresentam dificuldades em representar com exatidão alguns fenômenos meteorológicos e algumas características especificas de uma dada região, e por conta disso ocasionando erros na simulação do padrão do vento. Observou-se no estudo de Ramos, 2012 que o modelo atmosférico WRF (figura 06) apresentava um truncamento na variável velocidade de fricção em $0,1 \mathrm{~m} / \mathrm{s}$, ou seja, ventos fracos e áreas com baixa rugosidade não eram bem representados nas simulações. 


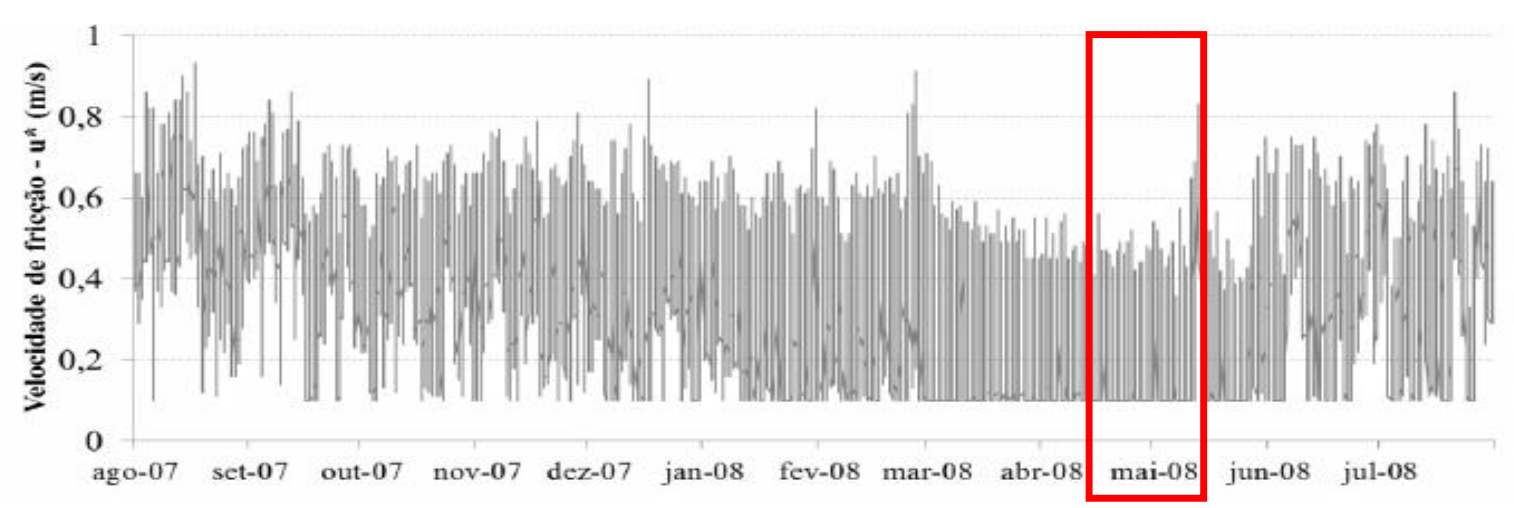

Figura 06: Variabilidade da velocidade de fricção do vento, para o município de Maragogi/AL, para o período entre 01/08/2007 - 31/07/2008. Fonte: Ramos, 2012

A figura 07 mostra a alteração realizada no valor de truncamento na velocidade de friç̧ão para $0,0001 \mathrm{~m} / \mathrm{s}$, o que permitiu representar as variações para caso de velocidade de friç̧ão abaixo de $0,1 \mathrm{~m} / \mathrm{s}$. No trabalho de Ramos, 2012 fez uso da variável velocidade de fricção para fazer a extrapolação vertical do vento a partir do nível $10 \mathrm{~m}$, seus resultados ficaram prejudicados nas simulações (ver figura 08A).

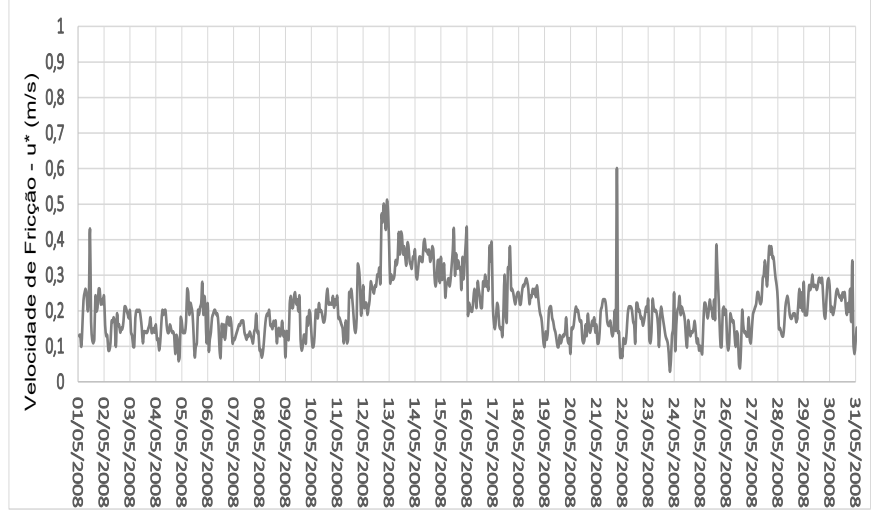

Figura 07: Variação da velocidade de fricção para o município de Maragogi/AL, durante o mês de maio de 2008.
A figura 08 mostra que a atualização da topografia, uso do solo, e velocidade de fricção, foram realizadas com sucesso, pois a variabilidade dos dados foram representadas pelo modelo WRF. Estatisticamente o coeficiente de correlação de PEARSON passou de 0,15 para 0,61, ou seja, no período onde o modelo apresentou maiores dificuldades nas simulações, as atualizações proporcionaram melhorias significativas nas simulações. Pode-se atribuir o peso maior para a melhoria das simulações a atualização da topografia e mudança no valor de truncamento da velocidade de fricção, pois a atualização feita para o uso do solo não gerou mudança expressiva. Notadamente o método de extrapolação do perfil vertical do vento utilizando o perfil logaritmo dependendo da velocidade de friç̧ão não foi a melhor solução para estimar o vento na área de estudo em questão, visto que o valor de truncamento de $\mathrm{u}^{*}$ foi reproduzido na velocidade do vento a $30 \mathrm{~m}$ de altura.

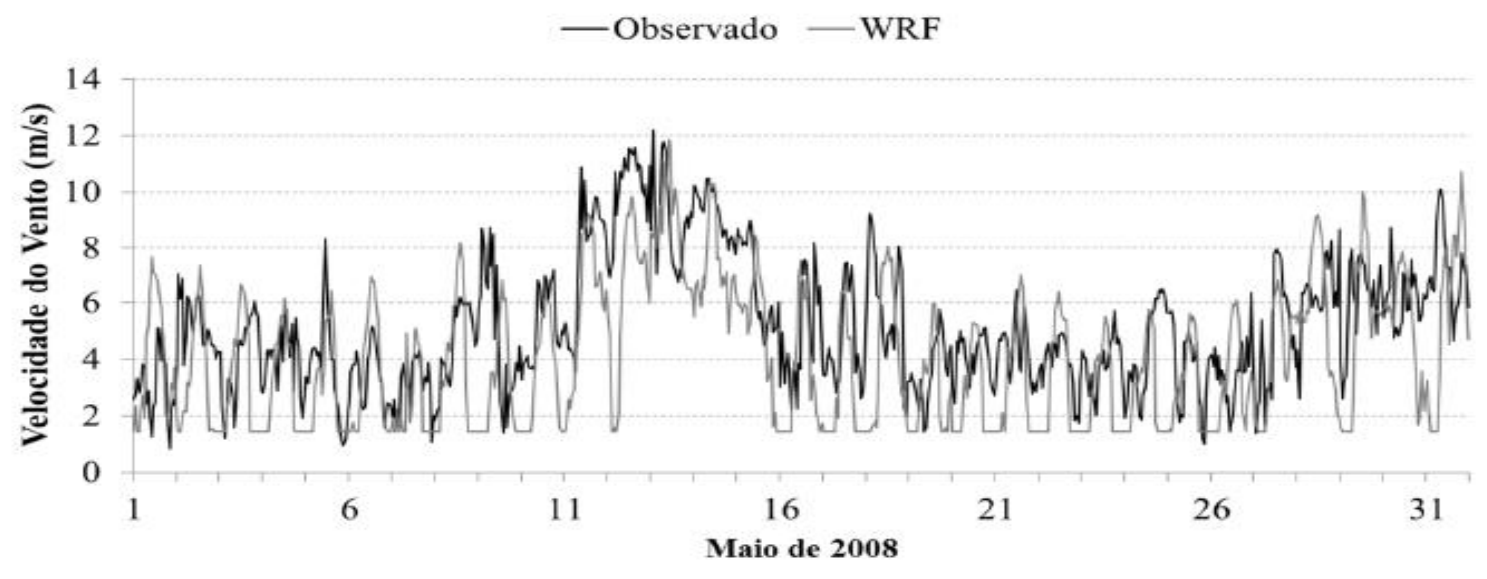

(a) Fonte: Ramos, 2012 


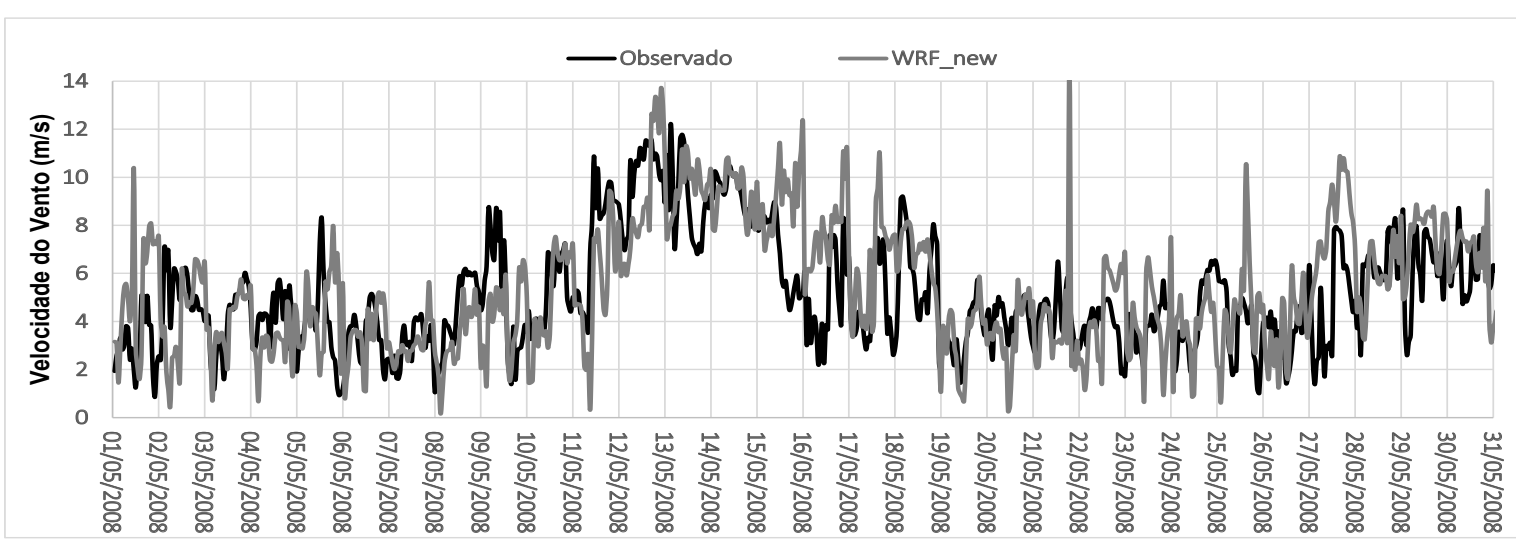

(b)

Figura 08: (a) Validação da velocidade do vento com a configuração padrão do modelo WRF, e (b) Validação da velocidade do vento com a atualização da topografia, uso do solo e velocidade de fricção.

\section{Conclusão}

A atualização da topografia tornou as simulações mais representativas (altura do relevo passou de $3,8 \mathrm{~m}$ para $30 \mathrm{~m}$ enquanto que o observado foi $48 \mathrm{~m})$. A atualização do uso do solo, tornou o entorno da área simulada mais representativa (não sendo considerada a vegetação nativa na simulação dita por padrão). E por se tratar de uma área litorânea sujeita a calmaria do vento, existiu a possibilidade de valor da velocidade de friç̧ão estar abaixo do truncamento do modelo $0,1 \mathrm{~m} / \mathrm{s}$, e a proposta de diminuir esse valor para $0,0001 \mathrm{~m} / \mathrm{s}$ tornou possível estimar com melhor eficiência a velocidade do vento, porém não sendo notada essa melhoria para a direção do vento.

As análises estatísticas comprovaram a melhoria quando implementados as atualizações de topografia, uso do solo e velocidade de fricção, tendo o coeficiente de correlação de PEARSON melhorado de 0,15 para 0,61 . E nas duas situações de simulação o modelo superestimou a intensidade do vento medida em Maragogi/AL.

Em termos de direção predominante do vento, as atualizações propostas não geraram mudanças significativas que justificassem a sua utilização, possivelmente por conta de ser região costeira e altura relativamente baixa do relevo.

\section{Agradecimentos}

Agradecimentos a FAPEAL (Fundação de Amparo à Pesquisa do Estado de Alagoas), e ao CNPq (Conselho Nacional de Desenvolvimento Científico e Tecnológico) pelo apoio financeiro concedido.
ARYA, S.P. Introduction to Micrometeorology, International Geophysics Series, Vol. 79, p. 420, 2001.

DE AMARANTE, O.A.C., 2001, Atlas do Potencial eólico Brasileiro. Brasília.

DE MARIA, P. H. S.; COSTA, A. A. e SOMBRA, S. S., 2008, MODELAGEM NUMÉRICA EM ALTA RESOLUÇÃO PARA PREVISÃO DE GERAÇÃO DE ENERGIA EÓLICA NO CEARÁ, Revista Brasileira de Meteorologia, v.23, n.4, $477-489 p$.

FOKEN, T. 50 years of the Monin-Obukhov similarity theory. Bound-Lay. Meteorol., v. 119, p. 431-447, 2006.

ELETROBRÁS, Atlas Eólico do Estado de Alagoas, v.1, 67p., 2008.

MME., Balanço Energético Nacional, ano base 2005. Ministério das Minas e Energia. 192p., 2006.

MONIN, A. S.; OBUKHOV, A. M. Basics laws of turbulent mixing in the surface layer of the atmosphere. Contrib. Geophys. Inst. Acad. Sci., USSR, 151, p. 163-187., 1954.

RAMOS, D. N. S. Mapeamento eólico do Estado de Alagoas utilizando ferramentas computacionais e dados observados. 2012. 130 p. Dissertação (Mestrado em Meteorologia) Universidade Federal de Alagoas (UFAL), Maceió (AL), 2012.

RAMOS, D.N.S., LYRA, R.F.F., SILVA JUNIOR, R.S. PREVISÃO DO VENTO UTILIZANDO O MODELO ATMOSFÉRICO WRF PARA O ESTADO DE ALAGOAS, Revista Brasileira de Meteorologia, v.28, n.2, 163 - 172, 2013.

SILVA, N. F.; ROSA, L. P.; ARAÚJO, M. R. The utilization of wind energy in the Brazilian electric sector's expansion. Renewable $\mathcal{E}$ Sustainable Energy Reviews, v. 9, p. 289-309. 2005.

SILVA JÚNIOR, R. S. et al. Análise da variação do potencial eólico utilizando o modelo WAsP.

\section{Referencias}


Anais do I Seminário Nacional de Engenharia do Vento (SENEV). Belo Horizonte: UFMG. P. 6, 2010a.

SILVA JÚNIOR, R. S. et al. Mapeamento do potencial eólico do Estado de Alagoas utilizando o modelo WRF. Anais do I Seminário Nacional de Engenharia do Vento (SENEV). Belo Horizonte: UFMG. P. 6, $2010 b$.

SKAMAROCK, W. C.; KLEMP, J.B.; DUDHIA, J.; GILL, D.O. BARKER, D.M.; WANG, W. POWERS, J.G., A Description of the Advanced Research WRF Version 2; NCAR Technical Note. 2005. 